\title{
Agent-based Modelling and Simulation for Population Dynamics under Agricultural Constraints in Prehistoric Hallstatt: Hints for a Second Settlement
}

\author{
J ohannes Tanzler ${ }^{1 *}$, Gabriel Wurzer ${ }^{2}$, Kerstin Kowarik ${ }^{3}$, Niki Popper ${ }^{1,4}$, Hans Reschreiter ${ }^{3}$, \\ Martin Bicher ${ }^{1,4}$, Felix Breitenecker ${ }^{1}$ \\ ${ }^{1}$ Institute of Analysis and Scientific Computing, Vienna University of Technology, Wiedner Haupstrasse 8-10, \\ 1040 Vienna, Austria; *johannes.tanzler@tuwien.ac.at \\ ${ }^{2}$ Institute of Architectural Sciences, Vienna University of Technology, Treitlstrasse 3, 1040 Vienna, Austria \\ ${ }^{3}$ Natural History Museum Vienna, Burgring 7, 1010 Vienna, Austria \\ ${ }^{4}$ dwh GmbH, Simulation Services, Neustiftgasse 57-59, 1070 Vienna, Austria;
}

Simulation Notes Europe SNE 26(1), 2016, 41 - 46 DOI: $10.11128 /$ sne.26.tn.10327

Received: November 20, 2015; Revised: March 3, 2016; Accepted: March 10, 2016;

Abstract. This contribution is an outcome of a project cooperation between the Museum of Natural History Vienna and the Vienna University of Technology. The museum investigates since many years the prehistoric salt mines in Hallstatt, Austria, by classical archaeological methods, by experimental archaeology, and by modelling and simulation, which partly ca be seen as virtual experimental archaeology. This contribution continues investigations on modelling agricultural constraints for population size in prehistoric Hallstatt, presented in a previous conference publication. As modelling and simulation approach agent-based simulation is used, as well for the mining process, and for the supply including food production, and for the environment. First, the supply for the mining process is studied. The main focus is on the food production and its time consumption which is needed to feed all people working and living in prehistoric Hallstatt. This time consumption consists at one hand of the actual time used for seeding, mowing and harvesting and on the other hand more importantly of the time used for traveling to the fields and harvesting the goods. To simulate the traveling time an $A^{*}$ algorithm is used, also for the traveling time needed for the miners to get to the mine. Also the supply process of felling and transporting trees to the mine as well as chipping the wood to produce wood chips for lighting purposes is part of the simulation. Experiments with the model try to localize suitable areas for the prehistoric Hallstatt village with interesting outcome: the simulation 'suggests' a subdivision of the population into a village near the mine and another village at the location of today's Hallstatt.

\section{I ntroduction}

Hallstatt is famous for its prehistoric salt mine which is of great interest for archaeologists. The special interest comes along with very well conserved finds which results of the great conserving effect of salt and the collapse of the salt mine in the $13^{\text {th }}$ century B.C. Some of these finds are very special tools and it is hard to understand in which way they were used. Not at last to get a better understanding of the way these tools were used a cooperation between the Museum of Natural History Vienna and the Vienna University of Technology was formed and this work is part of it. For instance a bronze pick which was investigated with the help of simulation in another project [1].

This work mainly focuses on the food production of the population of Hallstatt. It continues previous work on modelling agricultural constraints for population size in prehistoric Hallstatt, which studies how many people could have lived in Hallstatt if it is assumed that all food was produced locally [2]. The fields considered in this preliminary work are the same as used in this work. A result of this work is that 72 persons could have been fed of the food provided by these fields. This number of persons is used in the following as the population size. The population size is an essential parameter for this work because it directly influences the time needed to work on the fields.

The model which is used for this investigation is an agent-based one [3] and is implemented in Anylogic [4]. 


\section{The Model}

The basis for all agricultural production are the useable areas.

\subsection{Areas}

Because of the fact that this project is about prehistoric Hallstatt and its food production it would be desirable to know which areas they actually used and for which purpose. But unfortunately these data are not available so other data have to be used. The oldest data to get are data of the $19^{\text {th }}$ century. At this time maps for tax purposes were created and these maps hold information about the usage of the fields. These maps have been digitalised and can easily be implemented as shapefiles [5]. Because no better data are available, these maps are used for this project.

There are several different types of areas declared but the ones used are 'grass', 'field' and 'garden'. The total size of the class 'field' is 13 hectare and is used for two different crops. Half of it is used for sorghum production and the other half is used for barley production.

The 'garden' has a total size of 16 hectare and its crop is beans. Actually the size of the class 'grass' is over 650 hectare, but this would be too much to be used by 72 persons, more precisely the meat which could be produced by this amount

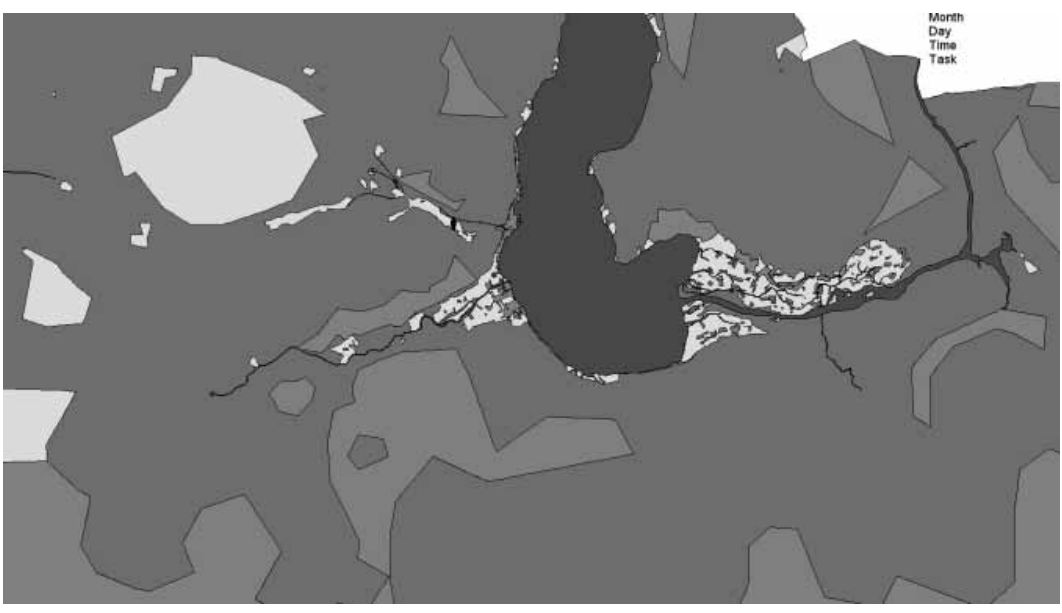

Figure 1: Used section of the map.

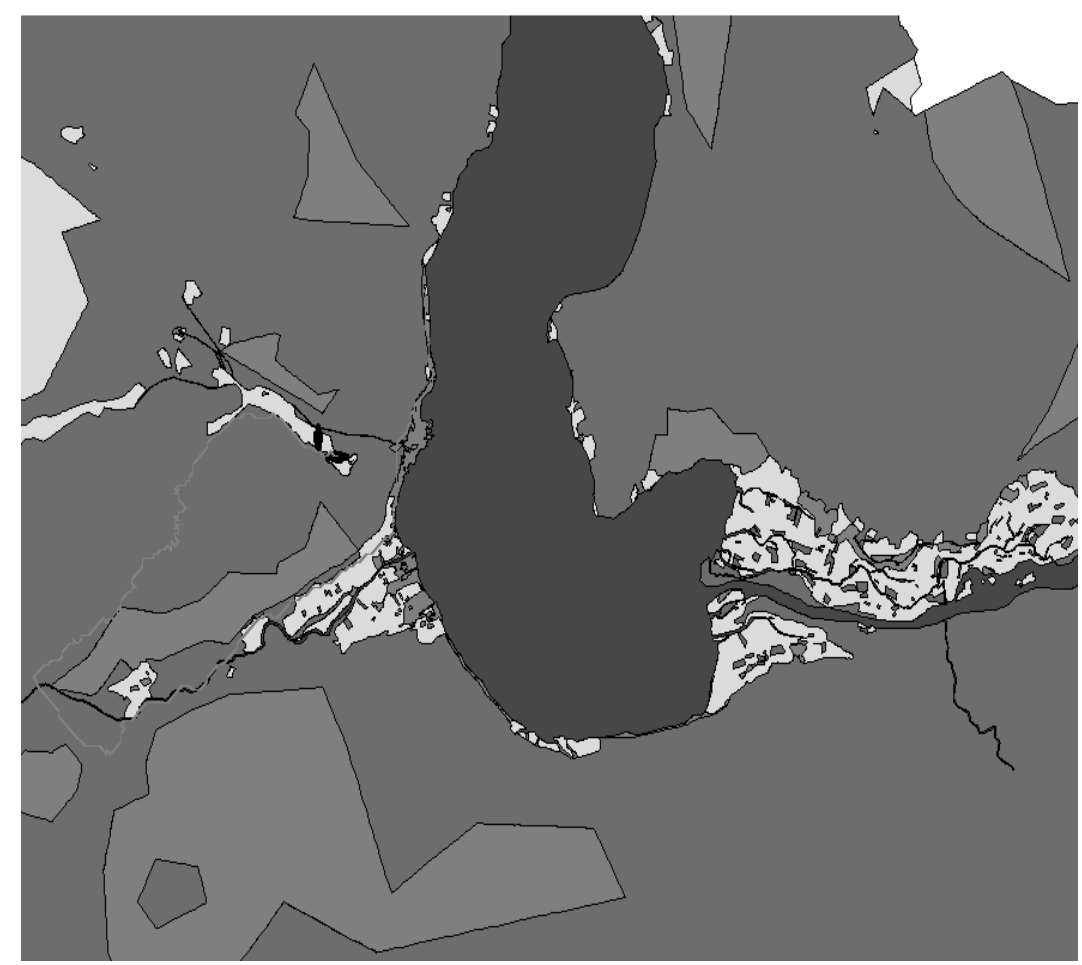
of grass would not guarantee a balanced nutrition. Therefore just the size of 100 hectare is supposed to be harvested. It also has to be said that no grazing is considered and all of these 100 hectare are mown and harvested.

Figure 1 shows the section of the map which is used for the simulation. The red areas are 'garden', the brown ones are 'field', the light green ones are 'grass', the dark green ones represent 'wood', grey is 'rock' and blue is 'water'.

\subsection{Calculation of the paths}

Because of the sectional very steep terrain it is necessary to use a good algorithm for the calculation of the paths. Therefore the used algorithm is an $A^{*}$ algorithm.

The disadvantage of using a complex algorithm is that the calculation needs lots of time especially if a small grid is used. In this case a grid of 25 meters seems to be the best choice. 
In Figure 2 a path from the village near the mine to a field near the lake is shown. It seems to be a loop way to the field, but actually this shows the steepness of the terrain because the $\mathrm{A}^{*}$ algorithm takes into account that the traveling speed is faster if the path is not too steep.

The steepness can be better seen in Figure 3. Blue coloured areas are the deepest ones and the green ones are the highest.

\subsection{Population}

Birth and death rates are basically gathered from the project 'Mining with agents' [6] and with these rates a population structure was calculated. As mentioned above the

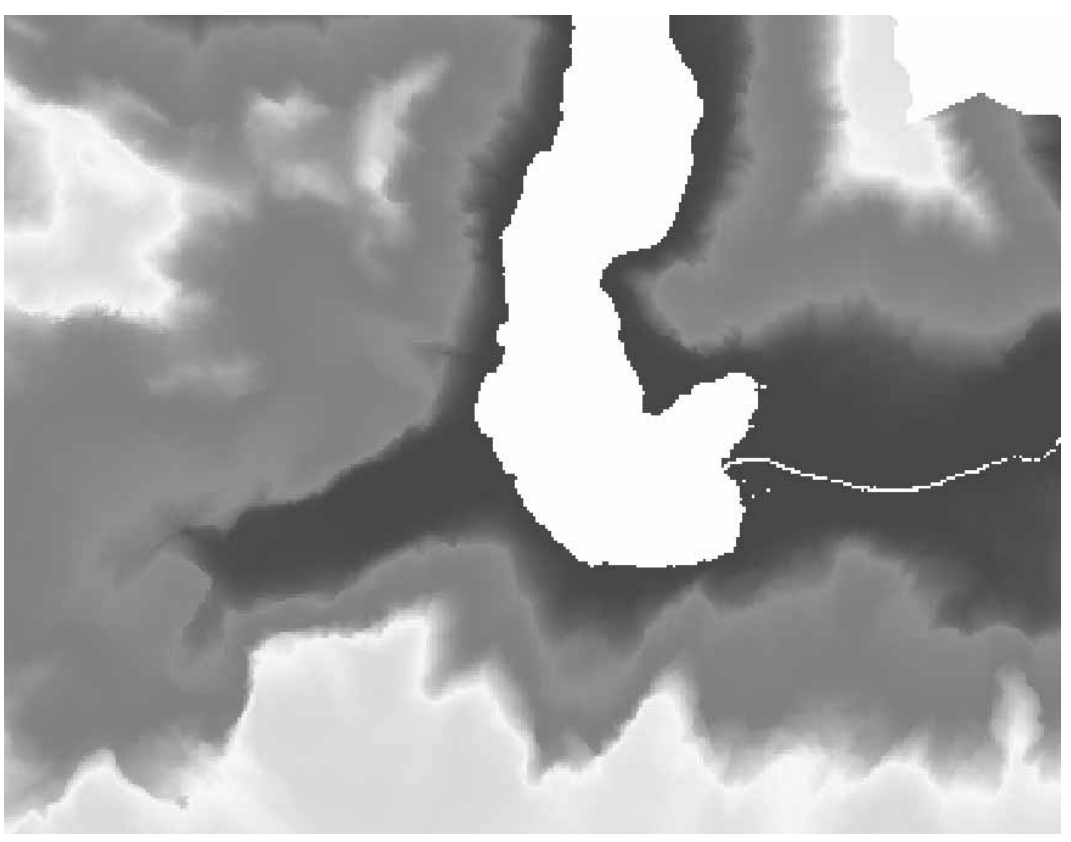

Figure 3: Depth model. population size is taken from a prior work [1] and is 72 .

Because of the calculated population structure not all of these 72 people are of an age which allows them to work. In this work it is assumed that persons younger than 6 years and persons older than 75 are not able to work. The following table shows the population structure and it can be spotted that 13 people are too young to work, no one is too old, what means that 59 persons are in an age where they can work.

\begin{tabular}{llllll}
\hline$[0 ; 6)$ & {$[6 ; 15)$} & {$[15 ; 30)$} & {$[30 ; 45)$} & {$[45 ; 75)$} & {$[75 ;$ Inf $)$} \\
\hline 13 & 20 & 21 & 11 & 7 & 0 \\
Pers. & Pers. & Pers. & Pers. & Pers. & Pers. \\
\hline
\end{tabular}

Table 1: Population structure.

As mentioned before this model is an agent based model and each person which is able to work is represented as an agent. Persons who are too young or too old are not modelled because they have no influence on the model.

\subsection{Working procedures}

The level of detail of the models concerning the working procedures is not very high but this does not seem to be necessary or useful. These models are kept simple so if there are better data, maybe by using experimental archaeology, they can be implemented easily.

Seeding and mowing. For these two procedures parameters called 'timeMowingPerHectar' and 'timeSeedingPerHectar' are used to define the seeding and mowing rates. In view of these rates an agent seeds or mows in every time step, when it is located at the field and the field is ready for seeding or mowing, a specific area. The parameters 'timeMowingPerHectar' and 'timeSeedingPerHectar' are both equal to 10 .

Harvesting. For harvesting a parameter called 'timeHarvestPerHectare' is used to represent the harvesting speed and is also 10. In this case the harvest speed is the same for each crop, even grass. But the most time consuming task concerning harvesting is not the harvesting itself but the transport of the goods to the home village of the agent because the physical highest load of each agent is set to $20 \mathrm{~kg}$.

Because of the time consuming task of transporting the crops the supposed yields of the crop plants are shown in Table 2.

\begin{tabular}{lllll}
\hline & sorghum & barley & beans & grass \\
\hline yield & $341.269 \mathrm{~kg}$ & $760.049 \mathrm{~kg}$ & $510.773 \mathrm{~kg}$ & $3000 \mathrm{~kg}$
\end{tabular}

Table 2: Yields. 
Wood production. This task is similar to harvesting but in this case another simplification is made, namely, all wood is gathered at one spot in the wood. The harvest rate of wood is set to $10 \mathrm{~kg}$ per minute and the transport capacity is $50 \mathrm{~kg}$, in contrast to $20 \mathrm{~kg}$ if carrying crop. A larger capacity is likely because there are finds that indicate a special method to drag wood.

Wood chip production. Wood which is dragged to the mine has to be chipped so it can be used for lighting purposes. This is also represented as a parameter called 'woodChipsPerMinute' which is set to $1 \mathrm{~kg}$.

Salt mining.The salt mining process itself is not modelled. The output of the salt mine is the time which is used in the mine. But every minute $0.5 \mathrm{~kg}$ wood chips are used in the mine.

\subsection{Scheduling of the workload}

The seducing of the workload is highly dependent on the date especially concerning the agricultural tasks. In the following Table 3 the optimal points in time for the agricultural tasks are shown, the numbers in this table represent the days of the year.

\begin{tabular}{lcccc}
\hline & sorghum & barley & beans & grass \\
\hline $\begin{array}{l}\text { seeding/ } \\
\text { mowing }\end{array}$ & 110 & 90 & 100 & 180 \\
\hline harvesting & 270 & 240 & 250 & 183 \\
\hline
\end{tabular}

Table 3: Action time table.

When the optimal day for a specific task has come, all fields of the specific class are activated and then processed. To be more precise - an agent gets a task assigned in the morning, then goes to the location of the field and performs it. Afterwards the agent gets the next task and directly heads to the next field which has not been processed yet.

To minimize the walking time it is estimated how many people have to work on the specific field. If every field has enough workers assigned, the workload is empty and no more agents have to walk down to the fields and are free to do other work. Should it happen that the estimation was not good enough and the field is not processed when it is time to call it a day, the field is taken back to the workload and will be processed at the next day.
On days when there is no agricultural work to be done, the agents are assigned to work in the mine if there are enough woodchips in the stock to light the mine. Otherwise the task is to make wood chips, or if there is not enough wood, to manage to get some.

\subsection{Second settlement}

As described before, the village is assumed to be located close to the mine and almost all fields beside the grass fields are located in the valley. This raises the guess that it could have made sense to have a second settlement in the valley, which would mean that not that many people have to go down to the valley for the agricultural purposes. Also not all the crop has to be brought up the hill because the people living in the valley can take their food with them when going to work in the mine. The down side is, that the people in the valley, who work in the mine, have to go up the hill every morning.

The possibility of a second settlement is taken into consideration and is placed in the valley where Hallstatt is located today.

\section{Results}

The result of this simulation is mainly the time which can be used to be spent in the mine because with this inferences on the salt output can be drawn.

Although the time spend in the mine maybe is not the most meaningful output. It seems more useful to take a closer look at the time spent for harvesting and seeding because the most uncertain parameters are taken into account the most - namely the rate of chipping wood chips per minute and the amount of chips needed per minute.

\subsection{Results one settlement}

When taking a closer look at the time needed for seeding in Figure 4 it can be seen that the time used for seeding is about 459 hours.

The time theoretically used for seeding is the area of fields and gardens times the seeding speed which would be about 290 hours but in these 459 also the time for traveling to the areas and back is included.

It is also easy to see in Figure 4 that the time used for working is close to exactly 8 hours a day. This is possible because in the simulation if the worker comes home late from work, the overtime is credited to the next morning. 


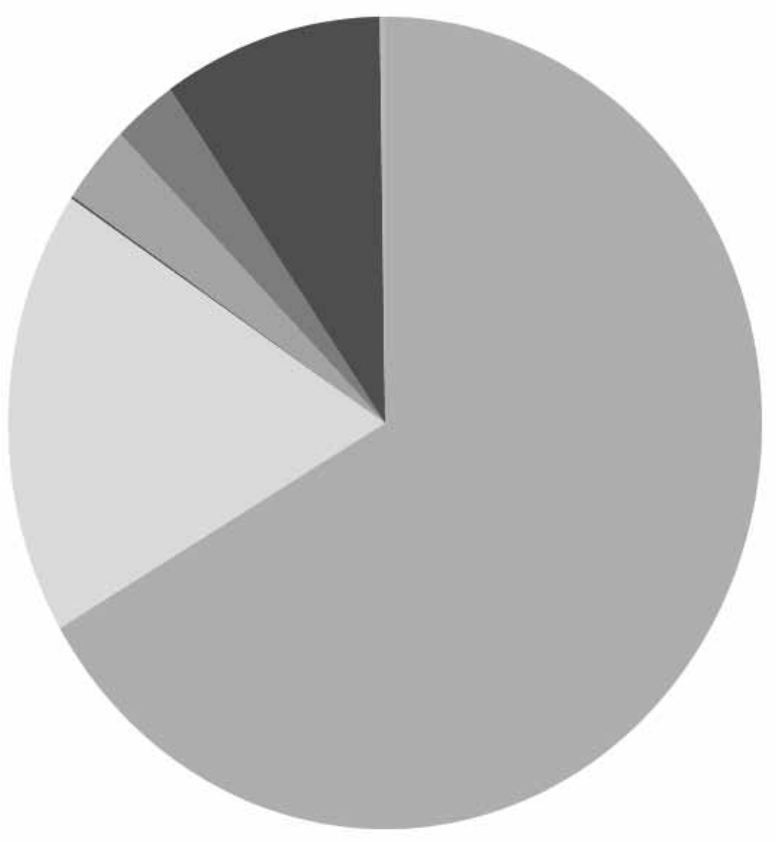

= timeRest: $343,785(66.6 \%)$

- timeseeding: $459(0.1 \%)$

- timewood: $14,181(2.7 \%)$ = timeMow: $1,147(0.2 \%)$

Figure 4: Time consumption.

Another thing to point out is that the time used for agricultural purposes seems quite low, especially if it is taken into account that a big area of 100 hectare grass has to be harvested.

\subsection{Results two settlements}

In this case the distribution of the people in the two settlements is studied.

Figure 5 shows that the more people live in the valley the shorter the time used for seeding is. Concerning the mowing time, the used time raises again when there are more than 45 people living in the valley. This is a result of the assumption that the people harvest the grass just in the valley and therefore they have to go around the lake to the right side of the lake to harvest grass and this path takes more time than going up the hill.

\section{Conclusion}

As the results have shown it really seems likely that there was a second settlement in the valley of Hallstatt. At the first look these results may look surprising but on the second look it is all about how often the people have to go up the hill.

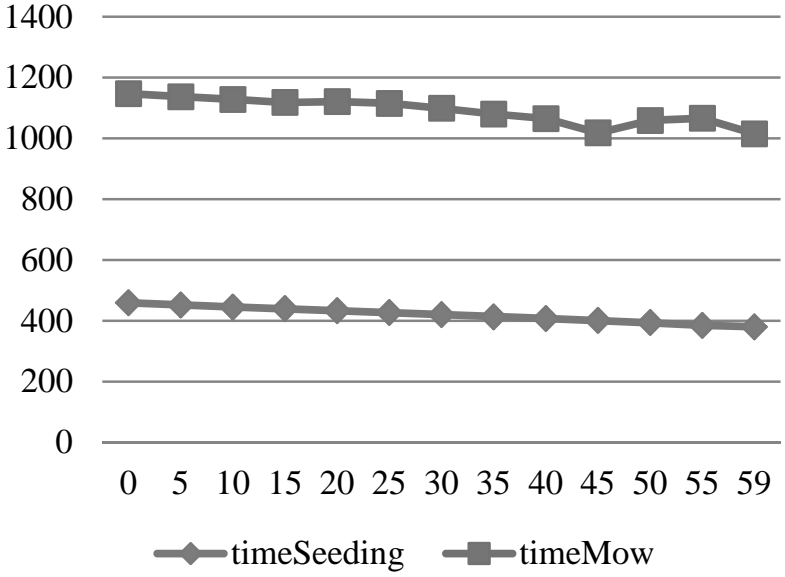

Figure 5: Time seeding and time mowing in dependence of the amount of people living in the valley.

The descending of the time consumption the more people live in the valley can be seen more dramatically in Figure 6.

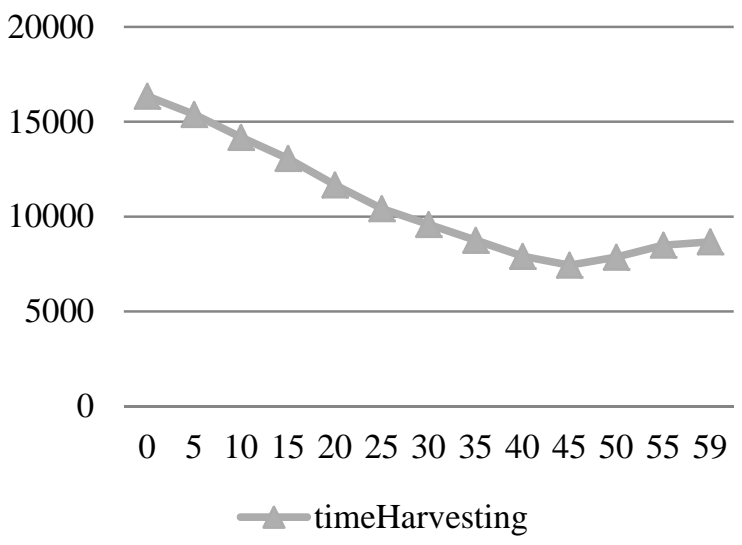

Figure 6: Time harvesting in dependence of the amount of people living in the valley.

If the amount of crop which can be transported at once could be raised a lot, it would be different at some point.

The fact that there are many more tasks which could be implemented and modelled more detailed, induces in doing so.

On the one hand it is questionable if also the results would get better on the other hand who can tell that they do not - the problem of validation in archeology. 


\section{References}

[1] Heinzl B, Auer E, Slowacki B, Kowarik K, Reschreiter $\mathrm{H}$, Breitenecker F. Mathematical modelling for experimental archaeology: case studies for mechanical tools in hallstatt salt mines. In: The 24th European Modeling and Simulation Symposium. 2012.

[2] Tanzler J, Pichler P, Kowarik K, Reschreiter H, Wurzer G, Bacher A, Breitenecker F. Modelling agricultural constraints for population size in prehistoric Hallstatt. ERK - International Electrotechnical and Computer Science Conference. 2013.

[3] Breitenecker F, Bicher M, Wurzer G. Agent-based modeling and simulation in archaeology, chapter: AgentBased Simulation in Archaeology: A Characterization. [S.1.]: Springer, 2013.
[4] Grigoryev I. AnyLogic 6 in three days: a quick course in simulation modeling. AnyLogic North America, Hampton, NJ, 2012.

[5] ESRI Shapefile Technical Description, An ESRI White Paper-July 1998.

[6] Kowarik K, Reschreiter H, Wurzer G, Totschnig R, Rausch A. Mining with Agents - Agent-based Modeling of the Bronze Age Salt Mine of Hallstatt, Talk: Archäologie und Computer, Wien; 11-03-2008 - 11-05-2008; in: "Workshop 13 - Archäologie und Computer 2008", CD der Stadt Wien, Stadtarchäologie, Wien (2009), ISBN: 978-3-85161-016-1; 1 - 19. 